\title{
Performance improvement of a crumb rubber modified bitumen using recycled glass powder
}

\author{
Mojtaba GHASEMI, Seyed Morteza MARANDI \\ (Department of Civil Engineering, Shahid Bahonar University, Kerman 7616914111, Iran) \\ E-mail: mghasemi59@eng.uk.ac.ir; marandi@uk.ac.ir \\ Received Feb. 14, 2013; Revision accepted July 9, 2013; Crosschecked Oct. 12, 2013
}

\begin{abstract}
In this study, the efficiency of bitumen and asphalt mixtures modified with crumb rubber (CR) and recycled glass powder (RGP) is evaluated. From an environmental point of view, the application of RGP in asphalt mixtures is considered beneficial since it prevents accumulation of waste glass in the natural environment. Rheological and mechanical properties of modified bitumen samples were investigated by laboratory methods such as bitumen conventional tests and dynamic shear rheometer (DSR), and also by asphalt mixture performance tests including Marshall stability, indirect tensile strength (ITS), compressive strength, and indirect tensile stiffness modulus. The results showed that the application of RGP in place of CR has no negative impact on the efficiency of bitumen and asphalt mixtures and even improves their engineering properties except for the toughness index (TI). Moreover, a modification with 5\% CR and 5\% RGP in asphalt mixtures results in the best overall performance.
\end{abstract}

Key words: Crumb rubber (CR), Recycled glass powder (PGP), Rheological properties, Performance testing, Stone matrix asphalt (SMA) doi: 10.1631 jzus.A1300053

Document code: A

CLC number: TU5

\section{Introduction}

One of the most important threats to the environment is the accumulation of waste materials such as rubber, glass, metal, plastic, etc. As the population increases, the amount of waste is rapidly growing and the disposal of waste has to be increased proportionally. There are three major ways to deal with waste materials: burying, incineration, and recycling. Recycling and reusing waste materials can be effective to reduce consumption of natural resources and also in mitigating environmental pollution (Batayneh et al., 2007; Marzouk et al., 2007; Canestrari et al., 2009).

With the increasing production of cars in recent decades, a huge amount of scrap tires is being generated worldwide. The scrap tires cannot be processed

(C) Zhejiang University and Springer-Verlag Berlin Heidelberg 2013 easily and therefore are considered as one of the most dangerous substances to the environment. Crumb rubber (CR), which is obtained from grinding the scrap tires, has been widely used in construction and industry. Particularly, CR has been used in the asphalt industry for more than four decades (Xiao and Amirkhanian, 2009; Xiao et al., 2009a; 2009b; 2009c). For instance, $\mathrm{CR}$ can be used as a bitumen modifier instead of expensive polymers such as styrene butadiene styrene (SBS) and styrene butadiene rubber (SBR) to reduce construction costs and energy consumption. This technique can also help reduce environmental pollution by recycling waste tires (Chiu and $\mathrm{Lu}, 2007$; Lee et al., 2008). Interestingly, in addition to the above-mentioned benefits, the combination of $\mathrm{CR}$ with bitumen improves the performance and engineering properties of asphalt pavements (Chiu and $\mathrm{Lu}, 2007$; Santagata et al., 2007; Canestrari et al., 2009; Cao, 2009; Kaloush et al., 2009; Partl et al., 2010). 
Many researchers have stated that the addition of $\mathrm{CR}$ to bitumen can improve the elastic function of bitumen and decrease the effects of aging. Therefore, it is considerably useful for producing asphalt pavements with the most durable service life, resistant to fatigue and thermal cracking, and having low maintenance costs, resistant to rutting and reflecting less traffic noise and lower thermal sensitivity (McNerney et al., 2000; Shen et al., 2005; Shen et al., 2006; California Department of Transportation, 2006; Xiao et al., 2007; 2009c). Because of all these advantages, bitumen modification with $\mathrm{CR}$ has become a common practice these days in the construction industry.

Glass, as a waste material, is produced more than 10 million tons annually in the world. However, it can be recycled frequently without change in its properties. In road construction, glass pieces have been used only as aggregate so far (Wu et al., 2004). A recent study carried out by Ghasemi and Marandi (2011) concerning the influences of recycled glass powder (RGP) on the physical and mechanical properties of SBS modified asphalt binders and mixtures, demonstrated improved performance of RGP-SBS modified pavements compared with conventional asphalt-mix pavements.

To have the aforementioned benefits of the CR modifier and further improvement of bitumen and asphalt, simultaneous effect of CR and RGP on engineering properties of bitumen and asphalt mixtures is investigated in the current study. The main objective of this study is to conduct a laboratory investigation into the influences of RGP on the physical and mechanical properties of CR-modified asphalt binders and mixtures.

\section{Materials and methods}

\subsection{Preparation of laboratory samples}

Pure bitumen with penetration grade 60-70 from the Isfahan Oil Refinery, Iran was used to make laboratory specimens. Engineering properties of pure bitumen are determined (Table 1).

The required $\mathrm{CR}$ was prepared from cutting, scraping and powdering waste tires and then adding it to the traditional bitumen to produce rubber asphalt. Powdering scrap tire and making CR can be done by ambient grinding or cryogenic grinding methods. If the process of making rubber powder is done at room temperature or higher, it is called ambient grinding. If the process of making rubber powder is done at $-120^{\circ} \mathrm{C}$ using liquid nitrogen to freeze off the rubber and thereby reducing its size, it is called cryogenic grinding. In the present study, CR was obtained from the ambient method. Lee et al. (2008) showed that the bitumen modified by ambient CR has more viscosity and less sensitivity to rutting and cracking. In this study, CR has a maximum size of $0.6 \mathrm{~mm}$ and a density of $1320 \mathrm{~kg} / \mathrm{m}^{3}$.

The other material for preparing samples is RGP which was obtained by the following two-step procedure: first, the waste glass was crushed by a hammer in a big metal container and then turned into powder in a ball mill for $10 \mathrm{~min}$; then the produced powder was passed through a sieve No. 200 (diameter less than $0.074 \mathrm{~mm}$ ). The density of obtained RGP was $2470 \mathrm{~kg} / \mathrm{m}^{3}$. The grain size distribution of RGP was derived using a laser particle size analyzer (Malvern Zetasizer Nano, UK) as shown in Table 2 (ASTM E1260, 2009).

Table 1 Conventional rheological properties of asphalt cement

\begin{tabular}{lcc}
\hline \multicolumn{1}{c}{ Item } & $\begin{array}{c}\text { Standard } \\
\text { ASTM }\end{array}$ & Value \\
\hline Penetration $\left(100 \mathrm{~g}, 5 \mathrm{~s}, 25^{\circ} \mathrm{C}\right)$, & D5-73 & 64 \\
$0.1 \mathrm{~mm}$ & & \\
Ductility $\left(25^{\circ} \mathrm{C}, 5 \mathrm{~cm} / \mathrm{min}\right)(\mathrm{cm})$ & $\mathrm{D} 113-79$ & $>100$ \\
Ductility after loss of heating test & D113-79 & $>100$ \\
$(\mathrm{~cm})$ & & \\
Solubility in trichloroethylene $(\%)$ & $\mathrm{D} 2042-76$ & 98.8 \\
Softening point $\left({ }^{\circ} \mathrm{C}\right)$ & $\mathrm{D} 36-76$ & 47.4 \\
Flash point $\left({ }^{\circ} \mathrm{C}\right)$ & $\mathrm{D} 92-78$ & 285 \\
Loss of heating $(\%)$ & $\mathrm{D} 1754-78$ & 0.03 \\
Specific gravity & $\mathrm{D} 70$ & 1.01 \\
\hline
\end{tabular}

Table 2 Particle size distribution of RGP

\begin{tabular}{cc||cc}
\hline Size $(\mathrm{nm})$ & $\begin{array}{c}\text { Percent } \\
\text { passing (\%) }\end{array}$ & Size (nm) & $\begin{array}{c}\text { Percent } \\
\text { passing (\%) }\end{array}$ \\
\hline 458.7 & 100.0 & 255.0 & 14.3 \\
396.1 & 99.6 & 220.2 & 0.6 \\
342.0 & 88.0 & 190.1 & 0 \\
295.3 & 52.4 & & \\
\hline
\end{tabular}

Microscopic morphology of RGP measured by the scanning electron microscopy (SEM) (Tech Solutions, USA) is illustrated in Fig. 1. The SEM 
examination shows that the glass powder particles are usually coarse, angular and flaky with a wide range of particle sizes. In order to determine the degree of absorption, a specific surface area test was performed on the RGP material according to the ASTM C204 standard. The RGP specific surface area was measured at $467 \mathrm{~m}^{2} / \mathrm{kg}$, indicates a high absorption.

Seven modified bitumen pieces were produced using CR-RGP to prepare a series of samples. Characteristics of the samples are shown in Table 3. Modified bitumen was generated with a laboratory scale mixer at $180{ }^{\circ} \mathrm{C}$ for $1 \mathrm{~h}$ and at a $3000 \mathrm{r} / \mathrm{min}$ rotational speed. The aggregate, used in asphalt concrete mixtures, was obtained from an asphalt plant in Kerman, southeastern Iran. Aggregate characteristics are presented in Table 4. Coarse and fine crushed aggregate with a maximum size of $19 \mathrm{~mm}$ were selected for the stone matrix asphalt (SMA) mixtures.

\begin{tabular}{|c|c|c|}
\hline Sample No. & $\begin{array}{c}\mathrm{CR}(\%, \\
\text { by binder weight) }\end{array}$ & $\begin{array}{c}\text { RGP }(\%, \\
\text { by binder weight) }\end{array}$ \\
\hline 1 & 10 & 0 \\
\hline 2 & 9 & 1 \\
\hline 3 & 7 & 3 \\
\hline 4 & 5 & 5 \\
\hline 5 & 3 & 7 \\
\hline 6 & 1 & 9 \\
\hline 7 & 0 & 10 \\
\hline
\end{tabular}

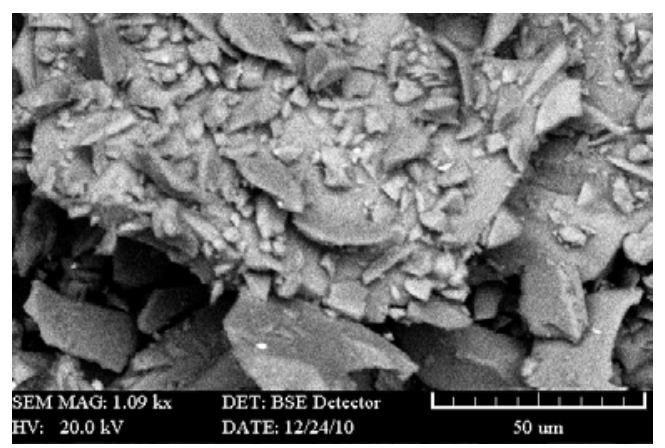

Fig. 1 SEM morphology of RGP
The aggregate gradation of the mixture is shown in Fig. 2.

\subsection{Dynamic shear rheometer (DSR) test of the binder}

Today, mechanical-dynamical methods based on oscillatory tests are acknowledged as the best way to evaluate the fundamental rheological properties of bitumen. These tests can be conducted with DSR. In the current study, DSR tests were performed on unmodified as well as modified bitumen with CR, RGP, and CR-RGP. The main results of the DSR testing include complex shear modulus $\left(G^{*}\right)$ and phase angle $(\delta) . G^{*}$ is defined as the ratio of maximum stress to maximum strain and represents overall resistance against deformation of the asphalt specimen under shear load. This experiment was conducted under conditions of controlled stress with a frequency of $10 \mathrm{rad} / \mathrm{s}(1.59 \mathrm{~Hz})$ and at a temperature of $64{ }^{\circ} \mathrm{C}$ in accordance with standard (ASTM D7175, 2008). According to this standard for high temperature tests $\left(46-82{ }^{\circ} \mathrm{C}\right.$ ), the samples should be of $1 \mathrm{~mm}$ thickness and $25 \mathrm{~mm}$ diameter.

\subsection{Binder conventional tests}

The base and modified bitumen (with CR, RGP and CR-RGP) were tested for the degree of penetration and softening point. Average results were calculated for three similar samples with the same modifier

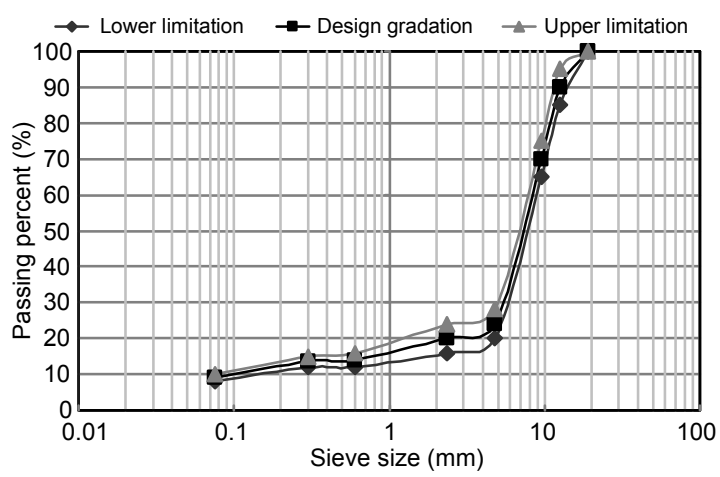

Fig. 2 Grain distribution curves of SMA

Table 4 Source and consensus properties of aggregates

\begin{tabular}{lccccc}
\hline \multicolumn{1}{c}{ Sample } & $\begin{array}{c}\text { Bulk specific } \\
\text { gravity }\end{array}$ & $\begin{array}{c}\text { Apparent specific } \\
\text { gravity }\end{array}$ & $\begin{array}{c}\text { Water } \\
\text { absorption (\%) }\end{array}$ & $\begin{array}{c}\text { Toughness } \\
(\%)\end{array}$ & $\begin{array}{c}\text { Soundness } \\
\left(\%, \mathrm{Na}_{2} \mathrm{SO}_{4}\right)\end{array}$ \\
\hline Coarse aggregate & 2.73 & 2.77 & 0.28 & 23.09 & 1.87 \\
Fine aggregate & 2.66 & 2.70 & 1.49 & - & 1.21 \\
Filler & 2.48 & 2.64 & - & - & - \\
ASTM standard & $\mathrm{C}-127 \&$ C-128 & & & $\mathrm{C}-131$ & $\mathrm{C}-88$ \\
\hline
\end{tabular}


content. Thermal sensitivity of the modified bitumen samples, which is the change of consistency parameter as a function of temperature, was evaluated by a penetration index (PI) as well as the results of the degree of penetration and softening point tests. The PI is calculated by (Read and Whiteoak, 2003)

$$
\mathrm{PI}=\frac{1952-500 \log \mathrm{Pen}_{25}-20 \mathrm{SP}}{50 \log \mathrm{Pen}_{25}-\mathrm{SP}-120},
$$

where $\mathrm{Pen}_{25}$ is the penetration grade of bitumen at $25^{\circ} \mathrm{C}$, and SP is the bitumen's softening point temperature. Compatibility between CR, RGP, and bitumen was investigated through the following techniques.

Uniform grain distributions for both $\mathrm{CR}$ and RGP and separation of larger grains were achieved using a sieve No. 100 at $170{ }^{\circ} \mathrm{C}$ (Punith and Veeraragavan, 2007).

Storage stability of CR-RGP modified bitumen was determined in accordance with regulations (ASTM D7173, 2011). The specimen was placed in an aluminum foil tube with a diameter of $32 \mathrm{~mm}$ and a height of $160 \mathrm{~mm}$. The tube was packed completely without even any air outlet and placed vertically in an oven at $163{ }^{\circ} \mathrm{C}$. After $48 \mathrm{~h}$, the tubes containing the modified bitumen were cooled to room temperature and cut horizontally into three equal parts. The upper and lower parts were melted separately and maintained in small containers named $\mathrm{T}$ and $\mathrm{B}$, respectively. When the difference between the $\mathrm{T}$ and $\mathrm{B}$ softening points became less than $2.5{ }^{\circ} \mathrm{C}$, the sample reached good storage stability (Wen et al., 2002; Ouyang et al., 2005).

\subsection{Marshall properties of asphalt mixture}

SMA mix design was conducted in accordance with the National Cooperative Highway Research Program No. 425 (NCHRP, 1999). Existing materials in the site that had acceptable specification, i.e., 60-70 penetration grade base bitumen, were used to prepare the reference mixture. Marshall specimens were constructed in the laboratory with 50 blows of a Marshall Hammer on each side. Optimum asphalt content was selected for the SMA mixture to achieve $4 \%$ air void and less than $0.3 \%$ drain down.

In this study, the optimum bitumen content for control samples was $6.1 \%$ to prepare all unmodified and modified SMA mixtures. Moreover, to eliminate the influence of bitumen content on analysis of experimental results, three samples of each mixture were made with identical bitumen content and the mean results were used as the outcome.

\subsection{Indirect tensile strength test of the asphalt mixture}

The indirect tensile strength test can be used to predict the fatigue potential and moisture sensitivity of asphalt mixtures. It has been shown that the ITS of the hot mix asphalt (HMA) is related to fatigue cracking (Goh et al., 2011). When the mixture has higher ITS, the asphalt pavement can withstand higher strain before failure or cracking. Furthermore, the moisture susceptibility of the asphalt mixture can be determined by comparing the ITS of the asphalt mixture under dry and wet conditions. In this study, Marshall specimens were used for the ITS test; additionally, the ITS of all samples was measured in accordance with standard (AASHTO T283, 2007). Indirect tensile strength tests were performed using a universal testing machine (Zwick, Germany) at a temperature of $25{ }^{\circ} \mathrm{C}$ and a deformation rate of $50.8 \mathrm{~mm} / \mathrm{min}$. ITS is calculated by

$$
\operatorname{ITS}=\left(2 P_{\max }\right) /(\pi d h),
$$

where $P_{\max }$ is the failure load $(\mathrm{N})$ of samples under diametric compressive loading, $d$ and $h$ are the mean values of the diameter $(\mathrm{mm})$ and height $(\mathrm{mm})$ of the Marshall samples, respectively. Moisture sensitivity of mixtures can be calculated using the indirect tensile strength ratio (ITSR) according

$$
\mathrm{ITSR}=\mathrm{ITS}_{1} / \mathrm{ITS}_{2},
$$

where ITS $_{1}$ and ITS 2 are the average ITS of the conditioned and unconditioned samples (both measured in $\mathrm{MPa}$ ). The toughness index (TI) is a parameter that describes characteristics of the after-peak region in the stress-strain curve. The index is calculated from indirect tensile strength test results (Huang et al., 2009). Stress and strain values are normalized by dividing them by the maximum stress and strain values. A dimensionless toughness index (TI) can be calculated by 


$$
\mathrm{TI}=\frac{A_{\varepsilon}-A_{\mathrm{p}}}{\varepsilon-\varepsilon_{\mathrm{p}}},
$$

where $\varepsilon$ is the strain (here $3 \%, 4 \%$, and $5 \%$ ) at the point of interest, $\varepsilon_{\mathrm{p}}$ is the strain corresponding to the peak stress, $A_{\varepsilon}$ is the area under the normalized stress-strain curve up to strain $\varepsilon$, and $A_{\mathrm{p}}$ is the area under the normalized stress-strain curve up to $\varepsilon_{\mathrm{p}}$. TI values vary from 0 (for an ideal brittle material) to 1 (for an elastic perfectly plastic material).

\subsection{Compression strength test of the asphalt mixture}

A compressive strength test was performed using a universal testing machine (Zwick, Germany). In order to apply compressive loads on the sample accurately, the two sides of the sample were made perfectly smooth and parallel to each other. Compressive strength tests were performed in load-controlled mode with a loading rate of $10 \mathrm{kN} / \mathrm{min}$ and the maximum load was recorded during the test. Ninetysix Marshall samples were used in this test in four different groups. The first group of samples was kept in air at normal temperature for $24 \mathrm{~h}$. The second group was kept in water at $25^{\circ} \mathrm{C}$ for $24 \mathrm{~h}$. The third group underwent 25 cycles of freezing and thawing as described as follows: These samples were first put in plastic bags with about $10 \mathrm{~mL}$ of water; subsequently, they were placed in the freezer for $4 \mathrm{~h}$ at $-20{ }^{\circ} \mathrm{C}$ and eventually let thaw for $4 \mathrm{~h}$ at $25^{\circ} \mathrm{C}$. The fourth group was placed in an oven for $4 \mathrm{~h}$ at $50{ }^{\circ} \mathrm{C}$. The three primary and the fourth groups were tested at $25^{\circ} \mathrm{C}$ and $50{ }^{\circ} \mathrm{C}$, respectively.

Compressive strength test results were used to obtain the following coefficients (Ahmedzade et al., 2007).

$$
K_{\mathrm{h}}=R_{25} / R_{50}
$$

where $K_{\mathrm{h}}$ is the coefficient of heat resistance, $R_{25}$ and $R_{50}$ are the compression strengths $(\mathrm{MPa})$ at $25^{\circ} \mathrm{C}$ and $50{ }^{\circ} \mathrm{C}$, respectively $(\mathrm{MPa})$.

$$
K_{\mathrm{f}}=R_{\mathrm{f}} / R_{\mathrm{w}},
$$

where $K_{\mathrm{f}}$ is the coefficient of frost resistance, $R_{\mathrm{f}}$ is the compression strength after 25 cycles of freeze-thaw (MPa), and $R_{\mathrm{W}}$ is the compression strength of the water absorbed specimen $(\mathrm{MPa})$. Then, $K_{\mathrm{w}}$ can be calculated by

$$
K_{\mathrm{w}}=R_{\mathrm{w}} / R_{25},
$$

where $K_{\mathrm{w}}$ is the coefficient of water resistance.

\subsection{Indirect tensile stiffness modulus test of the asphalt mixture}

Stiffness modulus of asphalt mixtures was measured under indirect tension conditions, which is the most common method of measuring the stress-strain relationship and evaluating the elastic properties as an important performance characteristic in pavement design. An indirect tensile stiffness modulus test (ITSM) was conducted according to British standard (BS DD 213, 1993), which is defined by $(\mathrm{MPa})$

$$
S_{\mathrm{m}}=F(R+0.27) /(L H)
$$

where $S_{\mathrm{m}}$ is the indirect tensile stiffness modulus, $F$ is the peak value of the applied vertical repeated load (N), $H$ is the mean amplitude of the horizontal deformation obtained from five applications of the load pulse $(\mathrm{mm}), L$ is the mean thickness of the test specimen (mm), and $R$ is the Poisson's ratio (assumed to be 0.35 ). The test was performed in controlled deformation conditions using a UTM. The target value of deformation was chosen as $6 \mu \mathrm{m}$. The rise time (defined as the time that the applied load is increased from zero to a maximum value) was $124 \mathrm{~ms}$. Application of the load pulse was set to $3 \mathrm{~s}$. Tests were carried out at $25^{\circ} \mathrm{C}$.

\section{Results and discussion}

\subsection{DSR test results}

$G^{*}$ and $\delta$ of unmodified and modified bitumen were measured at $64^{\circ} \mathrm{C}$. The ratio $G^{*} / \sin \delta$, called the rutting parameter, was determined for base bitumen and all samples Nos. 1-7, which are 82.78, 77.91, $72.49,69.26,65.32,70.11,73.54$, and 78.44, respectively.

Rutting parameters of modified samples with different RGP and CR contents are shown in Fig. 3. The results show that the rutting parameter values of 
the modified samples are increased to maximum values with increasing amounts of RGP up to $5 \%$. The maximum rutting parameter is obtained for the sample modified with $5 \% \mathrm{CR}+5 \% \mathrm{RGP}$; with progressive increase of RGP and reduction in $\mathrm{CR}$, the rutting value decreases. It is also clear that modified bitumen is more elastic than the base bitumen.

\subsection{Conventional bitumen test results}

The results of conventional bitumen test, including degree of penetration, flash point, ductility, specific gravity, loss of heating, and softening point tests are presented in Table 5. With changes in the amount of RGP and CR, penetration and softening point remain almost the same. Based on the results, it

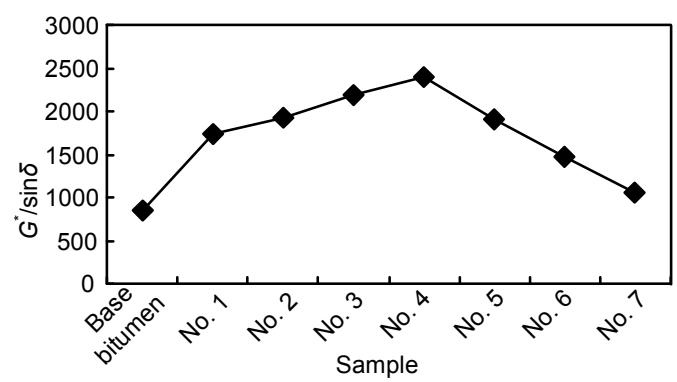

Fig. 3 Rutting parameter at $64^{\circ} \mathrm{C}$ for base and modified bitumen can be concluded that RGP has trivial effect on stiffness and elastic properties of bitumen.

Test results showed that the ductility of the modified samples is less than that of the unmodified samples. CR and RGP particles, which do not have the possibility of deformation in the narrowed section of the sample, cause the ductility to be reduced. Additionally, the current study revealed that by increasing RGP and decreasing CR in the CR-RGP modified bitumen, ductility increases. This is probably due to the smaller particle sizes of RGP in comparison with $\mathrm{CR}$, which lessens the effect in prevention of bitumen stretching.

Generally, a lower penetration index (PI) implies a higher thermal sensitivity. According to Table 5, PI values increase with increasing amounts of RGP and decreasing amounts of CR. Therefore, the thermal sensitivity of modified bitumen decreases with the addition of RGP to the mix and the resistance to low temperature increases.

\subsection{Marshall test results}

Marshall stability test results on specimens with constant bitumen content of $6.1 \%$ and different amounts of modifiers are summarized in Table 6. All results as well as the mean values are shown for each

Table 5 Basic properties of CR-RGP modified asphalt binders

\begin{tabular}{ccccccccc}
\hline Sample & $\begin{array}{c}\text { Penetration } \\
(\mathrm{mm})\end{array}$ & $\begin{array}{c}\text { Flash } \\
\text { point }\left({ }^{\circ} \mathrm{C}\right)\end{array}$ & $\begin{array}{c}\text { Ductility } \\
(\mathrm{cm})\end{array}$ & $\begin{array}{c}\text { Specific } \\
\text { gravity }\end{array}$ & $\begin{array}{c}\text { Loss on heating } \\
(\% \text {, in weight })\end{array}$ & $\begin{array}{c}\text { Top ring and } \\
\text { ball }\left({ }^{\circ} \mathrm{C}\right)\end{array}$ & $\begin{array}{c}\text { Bottom ring } \\
\text { and ball }\left({ }^{\circ} \mathrm{C}\right)\end{array}$ & $\begin{array}{c}\text { Penetration } \\
\text { index }\end{array}$ \\
\hline No. 1 & 57.2 & 251 & 40.2 & 1.012 & 0.65 & 56.5 & 58.9 & 0.90 \\
No. 2 & 56.9 & 259 & 54.8 & 1.026 & 0.59 & 56.6 & 58.8 & 0.87 \\
No. 3 & 56.5 & 263 & 58.8 & 1.055 & 0.52 & 56.9 & 59.1 & 0.92 \\
No. 4 & 56.1 & 281 & 65.5 & 1.084 & 0.43 & 57.1 & 59.2 & 0.94 \\
No. 5 & 55.8 & 287 & 70.0 & 1.113 & 0.38 & 57.2 & 59.2 & 0.94 \\
No. 6 & 55.7 & 292 & 72.9 & 1.142 & 0.24 & 57.6 & 59.6 & 1.02 \\
No. 7 & 55.5 & 296 & 87.7 & 1.156 & 0.15 & 57.7 & 59.9 & 1.05 \\
\hline
\end{tabular}

Table 6 Marshall design results of unmodified and modified mixtures

\begin{tabular}{ccccccc}
\hline Sample & Air void (\%) & $\begin{array}{c}\text { Voids in the mineral } \\
\text { aggregate }(\%)\end{array}$ & $\begin{array}{c}\text { Voids filled with } \\
\text { asphalt }(\%)\end{array}$ & $\begin{array}{c}\text { Marshall } \\
\text { stability }(\mathrm{kN})\end{array}$ & $\begin{array}{c}\text { Flow } \\
(\mathrm{mm})\end{array}$ & $\begin{array}{c}\text { Marshall quotient } \\
(\mathrm{kN} / \mathrm{mm})\end{array}$ \\
\hline Base bitumen & 4.33 & 14.92 & 70.11 & 6.82 & 4.00 & 1.71 \\
No. 1 & 4.12 & 15.23 & 72.94 & 10.13 & 2.99 & 3.39 \\
No. 2 & 4.01 & 15.82 & 72.64 & 9.76 & 2.75 & 3.55 \\
No. 3 & 4.08 & 15.00 & 72.75 & 11.08 & 3.01 & 3.68 \\
No. 4 & 4.10 & 15.05 & 72.72 & 10.49 & 2.76 & 3.80 \\
No. 5 & 4.11 & 15.24 & 72.93 & 10.45 & 2.84 & 3.69 \\
No. 6 & 4.00 & 15.89 & 72.13 & 10.09 & 2.75 & 3.67 \\
No. 7 & 4.09 & 15.01 & 72.74 & 9.94 & 2.71 & 3.67 \\
\hline
\end{tabular}


test. It can be generally inferred from Table 6 that the Marshall quotient (MQ) is increased to a maximum value as the RGP amount increases and the CR amount decreases. Nevertheless, further increases in RGP and decreases in CR result in a reduction of MQ. For asphalt mixtures, the maximum MQ is obtained with 5\% CR and 5\% RGP. In addition, MQ for all modified mixtures is higher than the control mixture and its maximum value is measured over two times higher than the control mixture. Consequently, it can be concluded that a significant improvement occurs in the Marshall properties of asphalt concrete mixtures using RGP modifier.

\subsection{Indirect tensile strength test results}

Fig. 4 depicts ITS test results for unconditioned asphalt samples with different percentages of modifier. These results show that by increasing percentage of the RGP, first the ITS is increasing to a maximum value, and then it is reducing. For asphalt mixtures, the maximum ITS is obtained with 5\% CR and 5\% RGP. The ITS of all modified samples were measured at a higher rate than the control sample. Moreover, the ITS of 5\% CR and 5\% RGP samples are about 25\% higher than the CR samples and about 50\% more than the unmodified samples.

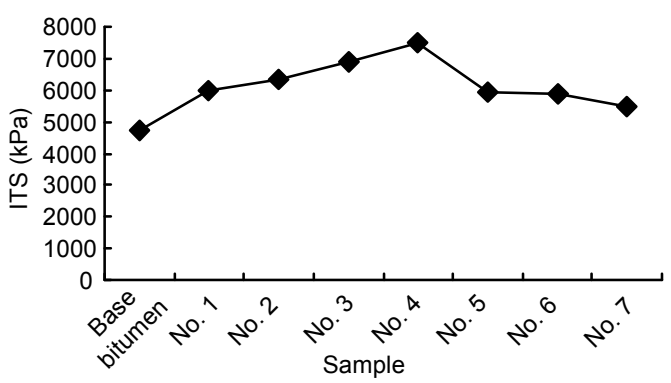

Fig. 4 Indirect tensile strength of unmodified and modified mixtures

Fig. 5 shows TSR for asphalt mixes. The results show that TSR increases to 0.96 with an increase in RGP. However, more increasing in the RGP percentage will result in TSR reduction. The maximum TSR is observed for the sample containing 5\% CR and $5 \%$ RGP. The strength of all mixes is higher than the minimum required $(75 \%)$.

The variation of TI against additive values is shown for different strain levels in Fig. 6. Fig. 6 shows that mixtures modified with different combinations of $\mathrm{CR}$ and RGP show similar behavior at different strain levels; moreover, TI initially decreases with the increase of RGP and decrease of CR and then increases after reaching the minimum. The minimum value differs at different strain levels. At 5\% strain, the modified sample with 9\% RGP and 1\% CR has a minimum TI value. While at $4 \%$ strain the minimum is observed for the sample with 5\% RGP and 5\% CR, and at 3\% strain for the sample with 1\% RGP and 9\% CR. Thus, it is found that mixtures modified only with CR or RGP show more elasticity than mixtures modified with different combinations of CR and RGP. Based on the test results, mixtures modified only with CR or RGP are expected to have a better resistance to fatigue stress.

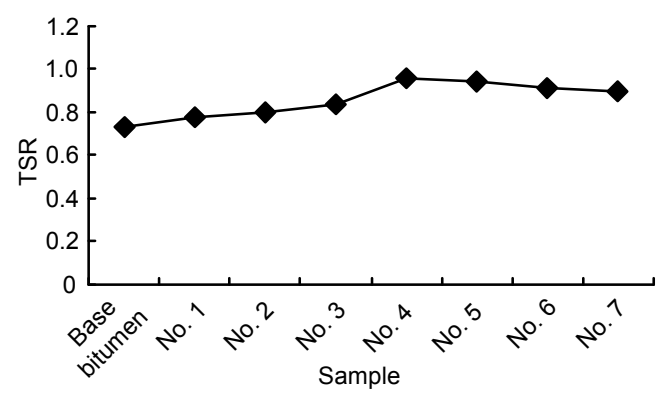

Fig. 5 Comparison of indirect tensile strength ratio for unmodified and modified mixtures

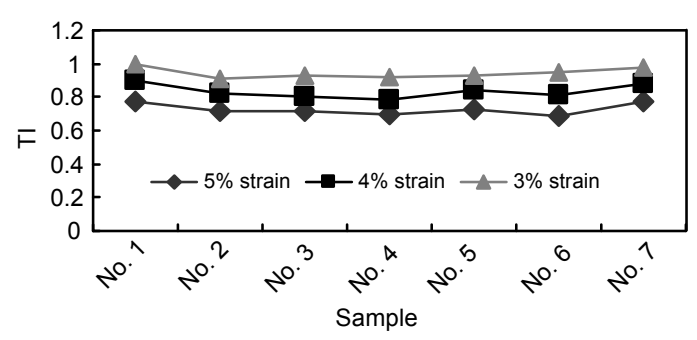

Fig. 6 Toughness index (TI) of CR-RGP modified mixtures

The results show that the values of TI increase as the strain level decreases, which suggests different performance for the same value of modifiers. In other words, the mixture efficiency is directly related to the strain level. Therefore, it can be concluded that the TI values should be evaluated at different strain levels to make a proper comparison between mixes.

\subsection{Compression strength test results}

Compression strength values for different mixtures are shown in Table 7 . On average, the mixture modified with 5\% RGP and 5\% CR has the greatest 
strength under different testing conditions as compared with the other mixtures. The average compressive strength of the mixture is about $15 \%$ higher than the control mixture. Moreover, when the CR content is higher than $7 \%$ in modified mixtures, the $R_{50}$ value is lower than the control mixture. Additionally, the results show that among the modified samples, saturated ones have the highest strength while those tested at high temperature have the lowest; the strength of the samples which have undergone freezing-thawing cycles commonly lie between these two. Overall, it can be deduced that RGP improves the compressive strength of SMA mixtures.

\subsection{Indirect tensile stiffness modulus test results}

Three samples were tested for each unmodified and modified mixture. To obtain a stiffness modulus for a mixture, each sample was tested in three different conditions and the average value was adopted. Stiffness modulus of the mixtures is shown in Fig. 7. The results show that mixtures modified with more RGP and less CR contents have higher stiffness modulus. All of the modified mixtures have a higher stiffness modulus than the control mixture, resulting in the pavement with less strain at lower temperatures.

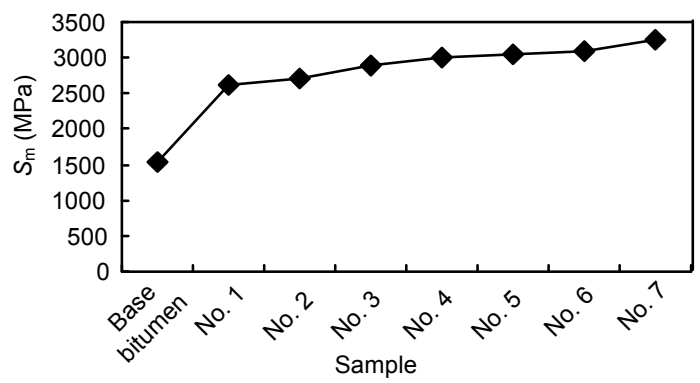

Fig. 7 Stiffness modulus of unmodified and CR-RGP modified mixtures

\section{Conclusions}

In this study a large number of bitumen and asphalt samples were examined during several laboratory tests. The results of this study are summarized as follows.

1. Bitumen modified with $\mathrm{CR}$ and RGP were more flexible than base bitumen. The maximum rutting parameter of the sample modified with CR and RGP was about $180 \%$ higher than the control sample and about $40 \%$ higher than the sample modified with CR.

2. RGP had trivial effect on the stiffness and elastic properties of the bitumen. The ductility of modified samples was less than the unmodified samples. However, with the increase of RGP and decrease of CR, ductility increased. On the other hand, the thermal sensitivity of modified bitumen reduced with the addition of RGP to the mixture and the lower temperature cracking resistance increased.

3. The value of MQ for all modified mixtures was higher than the control mixture. In addition, the maximum value of modified mixture MQ was over two times higher than the control mixture. Therefore, a significant improvement occurred in the Marshall properties of asphalt concrete mixtures using an RGP modifier.

4. The ITS of all modified samples was higher than the control sample. ITS of CR-RGP modified samples was also about $25 \%$ greater than CR modified samples and about 50\% higher than unmodified samples.

5. Mixtures modified only with CR or with RGP showed more elasticity than mixtures modified with different combinations of CR and RGP and, therefore, more resistant to formation and propagation of cracks. Moreover, the TI values should be evaluated at

Table 7 Compression strength test results

\begin{tabular}{cccccccc}
\hline Sample & $R_{50}(\mathrm{MPa})$ & $R_{\mathrm{f}}(\mathrm{MPa})$ & $R_{25}(\mathrm{MPa})$ & $R_{\mathrm{w}}(\mathrm{MPa})$ & $K_{\mathrm{w}}$ & $K_{\mathrm{h}}$ & $K_{\mathrm{f}}$ \\
\hline Base bitumen & 1.53 & 1.72 & 1.75 & 1.74 & 0.99 & 1.14 & 0.99 \\
No. 1 & 1.46 & 1.80 & 2.03 & 2.02 & 1.00 & 1.39 & 0.89 \\
No. 2 & 1.48 & 1.84 & 2.05 & 2.04 & 1.00 & 1.38 & 0.9 \\
No. 3 & 1.52 & 1.91 & 2.06 & 2.04 & 0.99 & 1.36 & 0.94 \\
No. 4 & 1.56 & 2.01 & 2.09 & 2.07 & 0.99 & 1.34 & 0.97 \\
No. 5 & 1.55 & 2.03 & 2.07 & 2.01 & 0.97 & 1.34 & 1.00 \\
No. 6 & 1.54 & 2.03 & 2.07 & 1.99 & 0.96 & 1.34 & 1.02 \\
No. 7 & 1.55 & 2.05 & 2.06 & 1.97 & 0.96 & 1.33 & 1.04 \\
\hline
\end{tabular}


different strain levels to make a proper comparison between mixtures.

6 . The average compressive strength of modified mixtures was higher than the control mixture. In addition, saturated modified samples showed higher levels of strength compared with samples experiencing cycles of freezing and thawing. Meanwhile, the minimum strength was observed in samples that had been at high temperatures. The samples modified with RGP showed much more resistance to cycles of freezing-thawing while samples modified with more $\mathrm{CR}$ showed more strength to the saturation.

7. Mixtures modified with more RGP had higher stiffness modulus than the control mixture and the pavement showed less strain at lower temperatures.

Overall assessment of the mechanical properties of asphalt mixtures showed that when RGP is applied, an improvement is observed in Marshall and mechanical properties. It was also inferred that rutting parameters, stiffness, and thermal sensitivity are improved with RGP entrance. Moreover, Marshall stability, ITS, compressive strength, and stiffness modulus of asphalt mixture increased with the increase of RGP content. The only foible in modification with RGP is the TI reduction. The optimal modification was attained with 5\% CR and 5\% RGP. Thus, RGP can be substituted partly for the CR in the bitumen modification. Application of RGP in asphalt mixtures also has many environmental benefits and helps prevent the accumulation of waste glass in the natural environment.

\section{References}

AASHTO T283, 2007. Standard Method of Test for Resistance of Compacted Asphalt Mixtures to Moisture-induced Damage, American Association of State and Highway Transportation Officials.

Ahmedzade, P., Tigdemir, M., Kalyoncuoglu, S.F., 2007. Laboratory investigation of the properties of asphalt concrete mixtures modified with TOP-SBS. Construction and Building Materials, 21(3):626-633. [doi:10.1016/j.conbuildmat.2005.12.003]

ASTM D7173, 2011. Standard Practice for Determining the Separation Tendency of Polymer from Polymer Modified Asphalt. [doi:10.1520/D7173-11]

ASTM D7175, 2008. Standard Test Method for Determining the Rheological Properties of Asphalt Binder Using a Dynamic Shear Rheometer. [doi:10.1520/D7175-08]

ASTM E1260, 2009. Standard Test Method for Determining Liquid Drop Size Characteristics in a Spray Using Optical Nonimaging Light-scattering Instruments. [doi:10.1520/
E1260-03R09]

Batayneh, M., Marie, I., Asi, I., 2007. Use of selected waste materials in concrete mixes. Waste Management, 27(12): 1870-1876. [doi:10.1016/j.wasman.2006.07.026]

BS DD 213, 1993. Method for Determination of the Indirect Tensile Stiffness Modulus of bituminous mixtures. British Standards Institution.

California Department of Transportation, 2006. Asphalt Rubber Usage Guide, USA.

Canestrari, F., Pasquini, E., Santagata, F.A., Antunes, I., 2009. Asphalt Rubber: Policy Disclosure in Italy. Asphalt Rubber Conference, Nanjing, China, p.967-988.

Cao, R., 2009. Evaluation of New Generation of Gap Graded Asphalt Rubber Mixtures. Asphalt Rubber Conference, Nanjing, China.

Chiu, C.T., Lu, L.C., 2007. A laboratory study on stone matrix asphalt using ground tire rubber. Construction and Building Materials, 21(5):1027-1033. [doi:10.1016/j.conbuildmat.2006.02.005]

Ghasemi, M., Marandi, S.M., 2011. Laboratory investigation of the properties of stone matrix asphalt modified with RGP-SBS. Digest Journal of Nanomaterials and Biostructures, 6(4):1823-1834.

Goh, S.W., Akin, M., You, Z., Shi, X., 2011. Effect of deicing solutions on the tensile strength of micro- or nanomodified asphalt mixture. Construction and Building Materials, 25(1):195-200. [doi:10.1016/j.conbuildmat. 2010.06.038]

Huang, B., Dong, Q., Burdette, E.G., 2009. Laboratory evaluation of incorporating waste ceramic materials into Portland cement and asphaltic concrete. Construction and Building Materials, 23(12):3451-3456. [doi:10.1016/j.conbuildmat. 2009.08.024]

Kaloush, K.E., Nordgren, T., Biligiri, K.P., Zeiada, W.A., Rodezno, M.C., Souliman, M.I., Reed, J., 2009. Laboratory Evaluation of Asphalt Rubber Gap Graded Mixture in Sweden. Asphalt Rubber Conference, Nanjing, China.

Lee, S.J., Akisetty, C.K., Amirkhanian, S.N., 2008. Recycling of laboratory-prepared long-term aged binders containing crumb rubber modifier. Construction and Building Materials, 22(9):1906-1913. [doi:10.1016/j.conbuildmat.2007. 07.012]

Marzouk, O.Y., Dheilly, R.M., Queneudec, M., 2007. Valorization of post-consumer waste plastic in cementitious concrete composites. Waste Management, 27(2):310-318. [doi:10.1016/j.wasman.2006.03.012]

McNerney, M., Landsberger, B., Turen, T., Pandelides, A., 2000. Comparative Field Measurements of Tire/Pavement Noise of Selected Texas Pavements. Center for Transportation Research, the University of Texas at Austin, Austin, TX, Report No. 7-2957-2.

NCHRP, 1999. Report 425: Designing Stone Matrix Asphalt Mixtures for Rut-Resistant Pavements. Transportation Research Board, National Research Council, Washington, DC.

Ouyang, C., Wang, S., Zhang, Y., Zhang, Y., 2005. Preparation and properties of styrene-butadiene-styrene copolymer/ 
kaolinite clay compound and asphalt modified with the compound. Polymer Degradation and Stability, 87(2): 309-317. [doi:10.1016/j.polymdegradstab.2004.08.014]

Partl, M.N., Pasquini, E., Canestrari, F., Virgili, A., 2010. Analysis of water and thermal sensitivity of open graded AR mixtures. Construction and Building Materials, 24(3): 283-291. [doi:10.1016/j.conbuildmat.2009.08.041]

Punith, V.S., Veeraragavan, A., 2007. Behaviour of asphalt concrete mixtures with reclaimed polyethylene as additive. Journal of Materials in Civil Engineering, 19(6): 500-507. [doi:10.1061/(ASCE)0899-1561(2007)19:6(500)]

Read, J., Whiteoak, D., 2003. The Shell Bitumen Handbook, Fifth Edition. Thomas Telford Publishing, Thomas Telford Ltd., London, p.62-136.

Santagata, F.A., Canestrari, F., Pasquini, E., 2007. Mechanical Characterization of Asphalt Rubber-wet Process. Proceedings of the 4th International SIIV Congress, Palermo, Italy.

Shen, J., Amirkhanian, S.N., Lee, S.J., 2005. Effects of rejuvenating agents on recycled aged rubber modified binders. The International Journal of Pavement Engineering, 6(4):273-279. [doi:10.1080/10298430500439319]

Shen, J., Amirkhanian, S.N., Xiao, F., 2006. High-pressure gel permeation chromatography characterization of aging of recycled crumb-rubber modified binders containing rejuvenating agents. Transportation Research Record: Journal of the Transportation Research Board, 1962:21-27. [doi:10.3141/1962-03]

Wen, G., Zhang, Y., Zhang, Y., Sun, K., Fan, Y., 2002. Rheological characterization of storage-stable SBS-modified asphalts. Polymer Testing, 21(3):295-302. [doi:10.1016/ S0142-9418(01)00086-1]

Wu, S., Yang, W., Xue, Y., 2004. Preparation and Properties of Glass-asphalt Concrete. Key Laboratory for Silicate Materials Science and Engineering of Ministry of Education, Wuhan University of Technology, Wuhan, China.

Xiao, F., Amirkhanian, S.N., 2009. Effects of binders on resilient modulus of rubberized mixtures containing rap using artificial neural network approach. Journal of Testing and Evaluation, 37(2):129-138. [doi:10.1520/JTE101834]

Xiao, F., Amirkhanian, S.N., Juang, C.H., 2007. Rutting resistance of rubberized asphalt concrete pavements containing reclaimed asphalt pavement mixtures. Journal of Materials in Civil Engineering, 19(6):475-483. [doi:10.1061/ (ASCE)0899-1561(2007)19:6(475)]

Xiao, F., Amirkhanian, S.N., Shen, J., 2009a. Effects of various long-term aging procedures on the rheological properties of laboratory prepared rubberized asphalt binders. Journal of Testing and Evaluation, 37(4):329-336. [doi:10.1520/ JTE101706]

Xiao, F., Amirkhanian, S.N., Shen, J., Putman, B., 2009b. Influences of crumb rubber size and type on reclaimed asphalt pavement (RAP) mixtures. Construction and Building Materials, 23(2):1028-1034. [doi:10.1016/j.con buildmat.2008.05.002]

Xiao, F., Zhao, W.B., Amirkhanian, S.N., 2009c. Fatigue behavior of rubberized asphalt concrete mixtures containing warm asphalt additives. Construction and Building Materials, 23(10):3144-3151. [doi:10.1016/j.conbuildmat.2009. 06.036] 